\title{
IMPOSIBLE FASCINACIÓN: UNA NOTA SOBRE LOS DIARIOS DE EMILIO RENZI DE RICARDO PIGLIA
}

Impossible Fascination: A note on Los diarios de Emilio Renzi by Ricardo Piglia

\author{
ÁlVARO MONGE ARÍSTEGUI \\ Universidad de Chile (Chile) \\ alvaromongea@gmail.com
}

\section{EL GÉNERO DIARIO}

En la actualidad se ha configurado un número importante de publicaciones, académicas y de otra naturaleza, que abordan diferentes aspectos de la (auto) biografía y el diario de vida como género literario. Esta profusión de escrituras en torno a lo íntimo y a lo privado, quizás, se debe a que las plataformas digitales han exacerbado la transmisión inmediata de hechos particulares (encuentros familiares, celebraciones) como el único horizonte de acontecimientos susceptibles de comunicar.

No obstante lo anterior, resulta útil sopesar, aunque sea de manera breve, algunas consideraciones respecto del género literario que nos ocupa. El diario de vida es un tipo de escritura paradigmática de la modernidad, al igual que géneros referenciales como la carta, las crónicas de vida, el ensayo y el reportaje. Leónidas Morales sostiene que dichos géneros -preexistentes algunos de ellos- se expanden y modifican en la segunda mitad del siglo XVIII, debido sobre todo a la crítica del principio de autonomía del arte y al distanciamiento del autor con su obra. La idea de llevar un diario íntimo se encuentra muy ligada a prácticas religiosas que son propias de la Reforma y Contrarreforma. De ahí la "costumbre de llevar un libro con la cuenta de los pecados, tentaciones y logros de cada día, como técnica auxiliar del examen y la regulación del comportamiento moral" (Morales, 1993, p.30).

El vasto campo de transformaciones impulsadas por la "revolución romántica" significó, en el ámbito de lo letrado, una emergencia preponderante del sujeto y su expresión, una constante preocupación por la subjetividad y sus manifestaciones. De este modo el diario íntimo se autonomiza de sus orígenes religiosos, para asentarse como género literario específico. El "diario íntimo" - en sus versiones más tradicionales- se caracteriza por acentuar la introspección y la memoria reflexiva. Es una escritura que nace desde la intimidad y debido a este origen es que, según Pérez Villalobos: "Un "diario se "lleva" como se lleva un hábito: como vestimenta insignificante, casi indistinguible con el cuerpo; como costumbre. No responde a un plan de obra, y ello porque un Diario no es más que el lugar donde van a dar las anotaciones del naufragio del día" (Pérez Villalobos, 2005, p.129). La intencionalidad de la escritura de un diario de vida no tendría un fin predeterminado con anterioridad y por ello el uso del fragmento como mecanismo de composición resulta consustancial a su ejercicio. El diario íntimo es, en 
términos de Olga Grau, "una escritura atravesada por el tiempo, en su manifestación fragmentada y calendarizada" (Grau, 2009, p. 34.).

Martín Cerda ha enunciado un vínculo entre la escritura del diario y ensayo que resulta pertinente de evocar al momento de leer Los diarios de Emilio Renzi:

El sujeto del diario no es, en consecuencia, alguien que se autocontempla o exhibe, sino un yo que se busca en la opacidad de los sucesos que lo ocupan y pre-ocupan: un sujeto que anota o registra en el curso cotidiano de su vida y, a la vez, lo observa piensa y comenta. Si los sucesos que anota aproximan al sujeto del diario al cronista, su reflexión continua sobre ellos lo avecina, en cambio, al ensayista (Cerda, 1982, p.97).

Por su parte, dice Renzi-Piglia:

De esa multiplicidad de fragmentos insensatos, había comenzado por seguir una línea, reconstruir la serie de los libros, "los libros de mi vida", dijo. No los que había escrito, sino los que había leído..."Como he leído algunos de mis libros" podría ser el título de mi autobiografia (si la escribiera) (2015, p.17).

Vemos coincidir en ambos autores una perspectiva crítica que interroga lo dado y no se limita a la reproducción pasiva de la realidad. Más aun; explicitan una aguda conciencia de la mediación por el lenguaje en la configuración de lo real. Al igual que el ensayista de Cerda, el sujeto de Los diarios de Renzi, pone en conexión reveladora la biografía y lo interpretativo, lo social y lo individual, lo estético y lo histórico.

\section{RASGOS DE LOS DIARIOS DE RENZI}

Los diarios de Emilio Renzi se dividen en tres volúmenes cuya fecha de inicio es 1957 y concluyen el 2015. Ellos son, de acuerdo con el orden de publicación: I Años de formación (2015), II Los años felices (2016) y III Un día en la vida (2017). En la recapitulación introductoria Renzi, alter ego de Piglia, refiere al origen de los diarios como el fundamento y condición de su obra: "Había empezado a escribir un diario a fines de 1957 y todavía lo seguía escribiendo. Muchas cosas cambiaron desde entonces, pero se mantuvo fiel a esa manía" (Piglia, 2015, p.11). Más adelante Piglia retoma esta cuestión, para resaltar el problemático vínculo del género diario con la actualidad. Esto último es relevante si consideramos el desfase propio del diario, del tiempo de la escritura y el de su difusión pública (con la expectativa, dicho sea de paso, de husmear en la intimidad de una figura reconocida de manera pública). Piglia es sarcástico al respecto:

Había transcrito las entradas de sus diarios de 1987 y las ajustó y las revisó, iba a publicarlas en una antología de la prosa autobiográfica en una editorial española, porque se había puesto de moda eso que los periodistas culturales y los fabricantes de papers académicos llamaban "la escritura del Yo", que se basaba en la conocida tentación de revelar secretos de la propia vida, previamente acomodados al sentido 
común general. La novedad consistía, según estos imbéciles, en que el autor se convertía en la estrella usando el procedimiento de llamar al personaje con su propio nombre. De inmediato todos aceptaban eso como verdadero, ya que el nombre propio y la figura del autor era, había pensado mientras caminaba hacia su guarida, la garantía de la cultura contemporánea (Piglia, 2017, pp.194-195).

Es importante hacer notar que el modelo binario de pensamiento es inherente a la obra de Ricardo Piglia. En su primera novela, Respiración artificial ${ }^{l}$ (1980) postula una oposición Borges-Arlt, como clave interpretativa de la literatura argentina. Según esta hipótesis Borges es el mejor escritor argentino del siglo XIX (ya que, a la vez, disuelve e integra las corrientes "europeísta" y "vernácula" que definen la época decimonónica) y Roberto Arlt es el mejor escritor del siglo XX ya que, en un gesto característico de la modernidad literaria, destruye la norma consagrada de estilo y corrección. Piglia piensa internamente el binarismo, y el sarcasmo ante las "escrituras del yo" que recién citamos no se coloca en un imposible lugar neutro, incontaminado, respecto del predominio avasallante de los medios de comunicación masivos y la clausura académica que circunscriben el trabajo del escritor en el presente. Dicho esto, es posible hacer notar que lo distintivo de esta trilogía es que constituye un diario descriptivo y no introspectivo: "Nada de vida interior, solo hechos, acciones, lugares, circunstancias que repetidas creaban la ilusión de una vida. Una acción - un gesto- que insiste y reaparece y dice más que todo lo que yo pueda decir de mí mismo" (Piglia, 2015, p. 16).

Así se entiende el rechazo que le producen los diarios de André Gide: "Me irrita su optimismo santurrón: pájaros que comen de su mano, montañas que se dejan escalar, peces que desarrollan frente a él su vida, etc.” (Piglia, Ricardo. 2016, p.79). Inclusive cuando se narran acontecimientos crudos, como los períodos de pobreza o la permanente tentación del suicidio, estos son aludidos desde el efecto de distanciamiento que produce el uso de la tercera persona.

A la manera del "joven Lukacs", de Brecht y de Benjamin, la obra de Piglia está cruzada por la historicidad de las formas estéticas - que es un modo de experimentar la existencia-. Para este linaje literario no existen formas estéticas al margen de las condiciones sociales, económicas y de poder que determinan una época. Un ejemplo que Piglia ha expuesto en variadas oportunidades es el de Edgar Allan Poe, reconocido como el creador del relato policial moderno. Auguste Dupin, el detective de Poe, así como su extensa progenie, que abarca desde Sherlock Holmes hasta Isidro Parodi, procede de acuerdo con una naturaleza sobre todo racionalista y deductiva. La novela policial "negra", desarrollada en Estados Unidos por escritores "menores" y "populares", como

\footnotetext{
${ }^{1}$ Aun teniendo presente la observación de Daniel Balderstone de que en Respiración artificial es Renzi y no Piglia quien piensa así. No obstante, reconoce el mismo Balderstone, "La obra de Borges le sirve a Piglia para pensar la literatura, en términos de estructura, género, entonación, lenguaje, sintaxis" (Balderstone, 2012, p.152). En tal sentido, pensamos, Piglia es un genuino borgeano y no un simple epígono.
} 
Hammett o Chandler, realiza un desplazamiento clave respecto del modelo original. El cambio principal se origina en la constatación de que la violencia y el dinero son el fundamento de la vida social moderna. No obstante, lo histórico de un texto literario, más que en las referencias de tipo contextual, se debe buscar en los procedimientos técnicos que lo construyen. En el caso de la literatura policial americana los diálogos son informativos y las descripciones de carácter estrictamente funcional, dice Piglia. También son agudos los análisis formales del rock, el tango y el jazz que, en diferentes momentos, Los diarios...desarrollan. Piglia tiene una notable capacidad para convertir un conjunto denso de lecturas en hipótesis penetrantes y formuladas con claridad.

En contraste con la retórica de la espontaneidad o del escándalo que muchas escrituras autobiográficas pretenden poner en escena la de Renzi-Piglia es ceñida y rigurosa. Por lo mismo descree de la confesionalidad - en tal sentido las referencias a los diarios de Kafka, "a las descripciones, a la vez algebraicas y líricas" (Piglia, 2017, p. 30) de sus cuadernos, o de Pavese, para quién "escribir es vivir y vivir es leerse". Es necesario comprender, dice Renzi-Piglia, que relato y concepto vienen juntos y no se debe pensar la literatura como un opuesto de la experiencia: "Siempre he rechazado la oposición entre pensamiento e ideas porque es el modo clásico de pensar de los anti intelectuales que abundan en el mundo cultural" (Piglia, 2016, p. 20).

Esta es una autobiografía serial, constituida por una multiplicidad de fragmentos, donde una escena da paso a otra, porque "Lo que se fija en la memoria no es el recuerdo, sino su forma" (Piglia, 2015, p. 19). El profesor Leónidas Morales sostiene que un diario siempre juega con la idea de un núcleo secreto que le constituya y que la violación de tal interdicto se encuentra a la base del interés que el género produce. En el caso de RenziPiglia, podriamos decir que el secreto consiste en la falta de secreto. Salvo uno que se encuentra a la luz del día: la consigna de "Primero ser un escritor y después escribir" (Piglia, 2015, p. 88). Los escritores que Piglia más admira -Hemingway, Borges, Kafkacoinciden en proponer un mito biográfico que sugiere una relación secreta entre texto y autor, entre biografía y obra. Secreta en el sentido de trastocar la visibilidad evidente del significado. La famosa teoría hemingwayana del iceberg -lo importante de una narración es el cuerpo sumergido y no la punta al descubierto- es nítida al respecto. El secreto es una información que ha sido ocultada y que como tal articula el relato. A diferencia del enigma, sostiene Piglia, se funda en un acto premeditado. Hemingway mismo cultivó con esmero la imagen de vividor despreocupado cuando, de verdad, está obsesionado en cómo escribir en inglés después de Joyce.

"Ser escritor" es enunciar, sobre todo, un deseo y por tanto una ilusión. La ilusión es lo que construye una vida y por tanto no se debe pensar que es un simple error. Es la forma más pura -siempre construida, en ningún caso natural ni espontánea- de la posibilidad. Aquí el modelo es Francis Scott Fitzgerald, en particular su novela El gran 
Gatsby, la historia de un hombre que quiere modificar el pasado, y estar a la altura de esa ilusión y de ese fracaso:

Fitzgerald fue capaz de realizar mejor que nadie la fantasía de ser un escritor. Uno no sería jamás tan famoso como un actor de cine, pero la notoriedad que se lograría sería probablemente más duradera: no tendría tampoco el poder de un hombre de acción pero sería por cierto más independiente (Piglia, 2015, p. 50).

Acerca del Diario escrito en la Estancia de Macedonio Fernández, ha dicho Piglia -y esto se aplica al diario de Renzi- que "En este Diario se entiende por qué el escritor no puede llevar sino el diario de la obra que no escribe" (Piglia, 2000, pp. 22-23). La pormenorizada descripción de las actividades cotidianas del escritor-periodismo, docencia, traducción- no son externas a la obra, ni tampoco la oportunidad de alardes narcisistas:

Son las cuatro de la mañana y, como siempre, al escribir entiendo mejor mi propia concepción de la literatura. Es el resultado y no la condición del trabajo de un escritor. Las ideas no son la condición sino el resultado de la escritura. El sentido de la literatura no es comunicar un sentido objetivo exterior, sino crear las condiciones de un conocimiento de la experiencia de lo real (Piglia, 2015, p. 244).

\section{LOS AÑOS DE LA PESTE}

Los años de la peste es la denominación que utiliza Piglia-Renzi para referir la dictadura militar que se instaura en Argentina desde 1976 hasta 1983. Un tiempo en el que la ciudad es asolada por una plaga que castiga a los ciudadanos en virtud de un crimen: "Un crimen estatal que producía - bajo la forma de una epidemia- en los ciudadanos el terror y la muerte" (Piglia, 2016, pp.12-13). En estas circunstancias se debe narrar teniendo a la peste no como un tema posible sino siendo condición misma del relato $^{2}$. Dice Renzi, parafraseando a Joyce, que "La narración alivia la pesadilla de la historia” (Piglia, 2017, p.13). ¿Cómo narrar aquellos sucesos que en primera instancia parecen inenarrables?:

Solo podemos nombrar las cosas que les ocurren a otras personas, nuestra propia experiencia vivida, nuestra existencia, nuestra sensación del paso del tiempo están demasiado próximas a nosotros como para ser visibles de un modo externo (de ahí la imposibilidad y fascinación de los diarios personales como este) (Piglia, 2017, p.131).

Característico del diario es registrar lo vivenciado con inmediatez, a diferencia de la evocación retrospectiva del memorialista. Dicho rasgo acentúa sus posibilidades

\footnotetext{
${ }^{2}$ Sin duda que un lector tan fino como Piglia tiene presente que Georg Lukács pensó, de manera preliminar, su Teoría de la novela, bajo la forma de un diálogo entre un grupo de jóvenes que se refugian de la peste en las afueras de la ciudad. El prólogo de Lukács para la reedición de 1967 de Teoría de la novela lo explicita(Lukács, 2010. p 6).
} 
expresivas cuando impera el "tiempo de la peste" y la vertiginosa sucesión de acontecimientos catastróficos, uno tras otro, que no dan tregua al narrador. Así leemos acerca de la detención -sin retorno- de un amigo, la siguiente entrada:

Leo el diario de Brecht, él también había perdido todo, pero no tenía miedo por las noches, ni lo despertaban los ruidos de la calle. ¿Qué se aprende en estas situaciones? A reconocer las determinaciones, la vida ya no depende de uno mismo. La realidad exterior invade de tal modo la iniciativa que parece absurdo hacer cualquier cosa, ya que nada se puede hacer para solucionar la cuestión principal (Piglia, 2017, p. 80).

Sí un recurso tradicional de la biografía es cerrarse con la muerte del biografiado, método que hace visible una pretensión de ordenamiento y secuencia, en el caso del diario parece ser el corte, la interrupción, su modo de clausura. Así ocurre con el ya mencionado diario de Pavese, quien se suicida tras escribir: "Basta de palabras, un gesto, no escribiré más" (Piglia, 2015, p. 146).

Las páginas finales de esta trilogía son, al mismo tiempo, la conclusión de una obra y de una vida, como el Diario de muerte, de Enrique Lihn ${ }^{3}$. En eso radica su poderosa melancolía. No se está escribiendo desde la muerte -sabemos que ello es imposible- sino desde la enfermedad y un progresivo declive:

Morir es difícil, algo me sucede, no es una enfermedad, es un estado progresivo que altera mis movimientos. Esto no anda. Empezó en Septiembre del año pasado, no podía abrochar los botones de una camisa blanca (Piglia, 2017, p. 293).

La muerte que, según Borges, "hace preciosos y patéticos a los hombres"4.

\section{OBRAS CITADAS}

Balderstone, Daniel (2012). “El Borges de Piglia” págs. 145-155 en Homenaje a Ricardo Piglia. Teresa Orecchia Havas (Ed). Buenos Aires: Catálogos.

Borges, Jorge Luis (2011). "El inmortal" en Obras completas. Vol I. Buenos Aires: Editorial Sudamericana.

Cerda, Martín (1982). La palabra quebrada. Ensayo sobre el ensayo. Valparaíso: Ediciones Universitarias.

Grau, Olga (2009), Tiempo y escritura: el Diario y los escritos autobiográficos de Luis Oyarzún, Santiago: Editorial Universitaria.

Lihn, Enrique (1989). Diario de muerte. Santiago: Editorial Universitaria.

${ }^{3}$ Dice Enrique Lihn: "Nada tiene que ver el dolor con el dolor/nada tiene que ver la desesperación con la desesperación/las palabras que usamos para designar esas cosas están viciadas/no hay nombres en la zona muda". ${ }^{4}$ Jorge Luis Borges, "El inmortal" en O.C.I: 842.

308 | AlPHA No 52 (JuLIO 2021) PÁGS. 303-309. ISSN 07 16-4254 
Lukács, Gyorgy (2010). Teoría de la novela. Un ensayo histórico filosófico sobre las formas de la gran literatura épica. Traducción de Micaela Ortelli. Buenos Aires: Ediciones Godot.

Morales, Leónidas (1995). "Introducción al diario íntimo de Luis Oyarzún” en Diario intimo, Luis Oyarzún Santiago: Universidad de Chile, Facultad de Ciencias Físicas y Matemáticas, Departamento de Estudios Humanísticos.

Pérez Villalobos, Carlos (2005). "Diario Íntimo y escritura" en Dieta de archivo. Memoria, crítica y ficción. Santiago: Universidad Arcis.

Piglia, Ricardo (2016a). Los diarios de Emilio Renzi. II. Los años felices. Barcelona: Anagrama.

__ (2016b). Los diarios de Emilio Renzi. III. Un día en la vida. Los años felices. Barcelona: Anagrama.

_ (2015). Los diarios de Emilio Renzi. I. Años de formación. Barcelona: Anagrama. (2000). Formas breves. Barcelona: Anagrama.

— (1980). Respiración Artificial. Buenos Aires: Pomaire. 